\title{
Treatment of Grade 2 and 3 Hemorrhoids with Doppler-Guided Hemorrhoidal Artery Ligation
}

\author{
B.M. Wallis de Vries ${ }^{a} \quad$ E.S.J. van der Beek ${ }^{a} \quad$ L.R.H. de Wijkerslooth ${ }^{a}$ \\ W.C. van der Zwet ${ }^{b} \quad$ J.A.B. van der Hoeven ${ }^{c}$ M. Eeftinck Schattenkerk ${ }^{a}$ \\ E.H. Eddes ${ }^{a}$ \\ Departments of a Surgery and ${ }^{b}$ Epidemiology, Deventer Hospital, Deventer, and ${ }^{c}$ Department of Surgery, \\ Academic Medical Center, Amsterdam, The Netherlands
}

\section{Key Words}

Hemorrhoids - Grade 2 and 3 hemorrhoids .

Doppler-guided hemorrhoidal artery ligation

\begin{abstract}
Aim: We evaluated the results of the Doppler-guided hemorrhoidal arterial ligation (DG-HAL) method in the management of symptomatic grade 2 and 3 hemorrhoids. Patients and Methods: Between June 2005 and March 2006, 110 consecutive patients with symptomatic grade 2 and 3 hemorrhoids according to the DG-HAL method were treated. All procedures were performed in daycare under spinal anesthesia. The primary objective was the reduction in hemorrhoidal gradation as determined by proctoscopy; the secondary was patient satisfaction. This was measured by interviewing patients over the telephone. Results: The average age was 47.6 years. 42 patients had grade 2 hemorrhoids, 68 grade 3. An average of 7.3 ligations were placed. Proctoscopy showed that, after 6 weeks, 97 (88\%) patients had a significant improvement in their hemorrhoidal gradation. After an average follow-up of 37 weeks, 93 of the 110 (84.5\%) patients were satisfied with the postoperative result. Mortality was $0 \%$ and morbidity $3 \%$. Conclusion: DG-HAL is a safe and effective treatment in the management of symptomatic grade 2 and 3 hemorrhoids.

Copyright $\odot 2007$ S. Karger AG, Basel
\end{abstract}

\section{Introduction}

Hemorrhoids are a common disease in the western world. The incidence is estimated at $8 \%$, the prevalence at $10 \%$. The male:female ratio is 1:4 [1]. Although many treatment modalities have been described in the literature, there is no golden standard in treatment. The lack of consensus is partially based on the fact that the indi-cation to treat is based on the subjective severity of the symptoms, while the choice of treatment is based on the gradation of the hemorrhoids and local experience [2,3].

Traditionally, the initial treatment for grade 1,2 and 3 hemorrhoids is conservative management (fiber-rich diet and better defecation discipline) $[1,4]$. If symptoms prevail, there is a wide range of treatment modalities. Injection sclerotherapy is an outpatient procedure that stops the bleeding and has a low rate of complications. However, it is not helpful in treating a prolapse. Its main disadvantage is its low efficaciousness $[4,5]$. Infrared coagulation is another outpatient procedure. There are usually few complications, but it is not very effective against prolapse. The results of infrared coagulation on non-prolapsing hemorrhoids appear to be better than with injection sclerotherapy [6]. An outpatient treatment that seems to be more effective for both bleeding and prolapse is rubber banding. Meta-analyses have shown that rubber

\section{KARGER}

Fax +4161306 1234 E-Mail karger@karger.ch www.karger.com

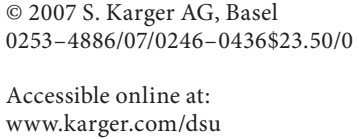

Dr. B.M. Wallis de Vries

Department of Surgery, Deventer Hospital

Postbus 5001, NL-7400 GC Deventer (The Netherlands)

Tel. +31 62902 4467, Fax +31 570629144

E-Mail bmwallisdevries@home.nl 

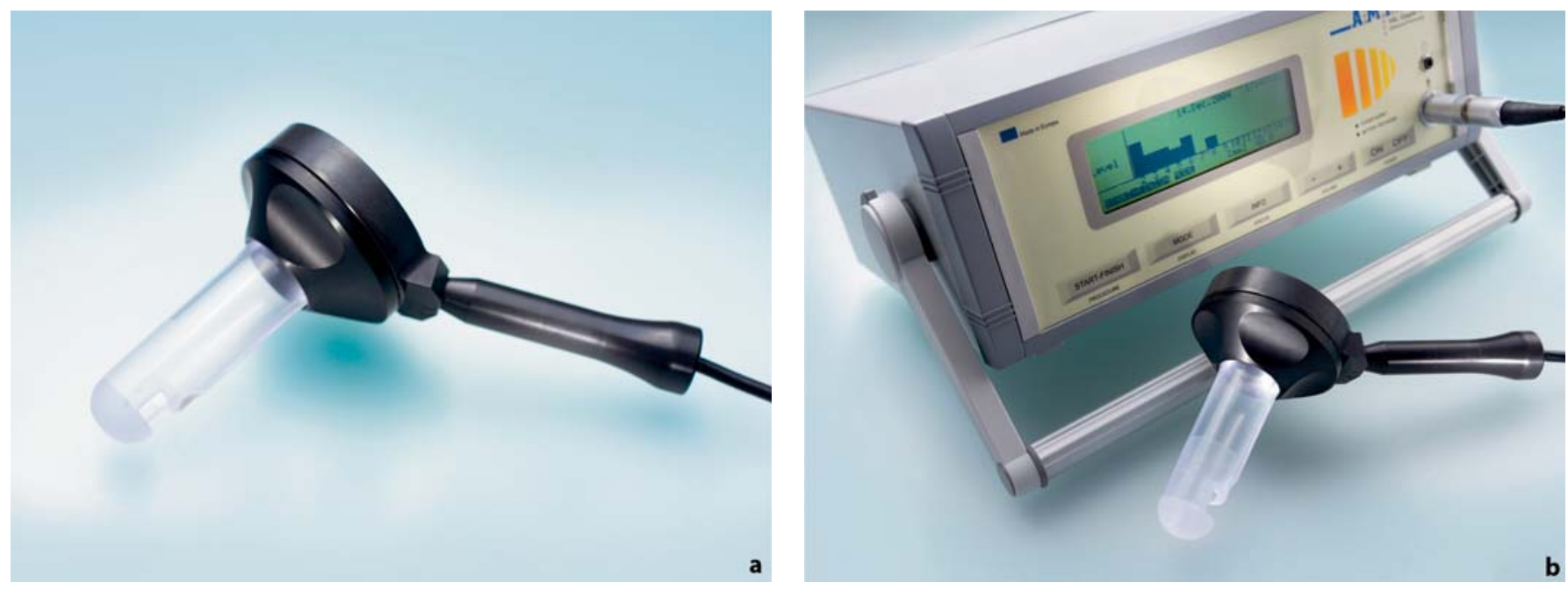

Fig. 1. a Disposable proctoscope with the Doppler transducer on the tip. $\mathbf{b}$ The proctoscope connects to the Doppler device and produces easily recognizable acoustic signals.

banding is more effective in both the short and long term compared to photocoagulation and infrared coagulation. Overall, it appears that between 60 and $80 \%$ of patients who have undergone banding are satisfied with the outcome [6-9]. However, this procedure also has disadvantages. One that is often reported is the posttreatment pain. Finally, a form of hemorrhoidectomy (open, closed or stapled) is still used by some as a primary treatment option. Hemorrhoidectomy is associated with more pain and morbidity than rubber banding. This treatment is generally reserved for persistent grade 3 and 4 hemorrhoids $[1,10,11]$.

In the past decade, a new method was introduced in which the arterial blood supply of the hemorrhoidal plexus are bound with ligatures. The superior hemorrhoidal plexus is supplied with blood by the superior rectal artery [12]. Hemorrhoids occur when there is an imbalance in the blood flow of this plexus, with either an increased arterial inflow, or a decreased venous drainage. Dopplerguided hemorrhoidal arterial ligation (DG-HAL) was first described in 1995. By combining a proctoscope with a Doppler transducer, it became possible to detect the arterial inflow of the plexus and selectively ligate the vessels. By reducing the inflow, the plexus diminishes and the hemorrhoids shrink [13]. This seems especially effective in grade 2 and 3 hemorrhoids [14].

In this study, we describe the results of the DG-HAL technique in the treatment of grade 2 and 3 hemorrhoids.

\section{Patients and Methods}

Our aim was to evaluate the results of the DG-HAL method in the management of symptomatic grade 2 and 3 hemorrhoids. All patients with symptomatic grade 2 and 3 hemorrhoids were eligible for a DG-HAL procedure. The outpatient procedure was performed in daycare under spinal anesthesia. Three hours prior to surgery, the patients received a phosphate enema. We used the DG-HAL system from AMI. Figure la shows the disposable proctoscope with the Doppler transducer on the tip. There is an opening slightly distally from the transducer through which the ligature can be placed in the tissue. The proctoscope connects to the Doppler device and produces easily recognizable acoustic signals (fig. 1b). After an arterial signal is detected, it is ligated. After ligation, the absence of an arterial signal on that spot is confirmed with the Doppler transducer. Three full circles with the proctoscope are performed in the rectal canal with the proctoscope and every arterial signal is ligated. The ligations were performed with a vicryl stitch especially made for this procedure (AMI HAL suture, $2 / 0$ vicryl, tapered needle, 5/8 circumference, reinforced needle-thread connection). All patients were evaluated with a proctological examination 6 weeks postoperatively. Further evaluation was performed by telephone. The pre- and postsurgery examinations, as well as the procedure itself, were done by a selected group of doctors with extensive experience in proctology. The primary objective of this study was the postoperative hemorrhoidal gradation. The secondary objective was patient satisfaction.

\section{Statistical Analysis}

Analysis was performed with the SPSS Statistical Package version 12.0 (SPSS Inc., Chicago, Ill., USA) and Excel 2000 (Microsoft, Redmond, Wash., USA). Comparison of pre- and postoperative hemorrhoid grading was performed using the Wilcoxon matched pairs rank sum test. $\mathrm{p}<0.05$ was considered significant. 


\section{Results}

In the period June 2005-March 2006, 110 patients underwent a DG-HAL procedure. The average age was 47.6 years (median 46, range $25-80$, interquartile range 18.5 ). The male:female ratio was 64:46. 42 patients had grade 2 hemorrhoids, 68 had grade 3 . Ten patients received a second DG-HAL procedure. An average of 7.3 ligations were placed (median 7, range 1-16). Analysis did not reveal a preferred location for the ligations; they were equally distributed along the circumference of the rectal canal. The average procedure duration was $16 \mathrm{~min}$ (range 12-23). A postoperative evaluation was performed by proctoscopy after 6 weeks. 97 (88\%) patients had an improvement in their hemorrhoidal gradation, a significant result $(\mathrm{p}<$ 0.001, Wilcoxon signed ranks test). Postoperatively, 46 patients (42\%) no longer had hemorrhoids (grade 0), 42 $(38 \%)$ had grade $1,12(11 \%)$ had grade $2,9(8 \%)$ grade 3 , and $1(1 \%)$ had grade 4 hemorrhoids (table 1$)$.

Further follow-up was done by an enquiry by phone. After an average follow-up of 37 weeks (median 35, range
22-58), 93 of the $110(84.5 \%)$ patients were satisfied with the postoperative result. Ten patients underwent a second DG-HAL procedure after 3 months. Nine of these patients were unsatisfied after the first procedure because of persistent prolapse; 1 patient complained of persistent bleeding. After the second procedure, 4 were still unsatis-

Table 1. Gradation of hemorrhoids before and after surgery

\begin{tabular}{|c|c|c|c|c|c|}
\hline & & re & gery & & \\
\hline & 0 & 1 & 2 & 3 & 4 \\
\hline After & & & & & \\
\hline 0 & & & 22 & 24 & \\
\hline 1 & & & 17 & 25 & \\
\hline 2 & & & 3 & 9 & \\
\hline 3 & & & & 9 & \\
\hline 4 & & & & 1 & \\
\hline
\end{tabular}

Improvements are shown in bold.

Table 2. Results of the patients who underwent a second DG-HAL

\begin{tabular}{lllll}
\hline Sex & Age & Grade pre- $\rightarrow$ postoperative & Result after 1st procedure & Result after 2nd procedure \\
\hline $\mathrm{M}$ & 37 & $\begin{array}{l}\text { 1st procedure: } 2 \rightarrow 2 \\
\text { 2nd procedure: } 3 \rightarrow 1\end{array}$ & $\begin{array}{l}\text { unsatisfied } \\
\text { (persistent prolapse) }\end{array}$ & satisfied \\
\hline $\mathrm{F}$ & 62 & $\begin{array}{l}\text { 1st procedure: } 3 \rightarrow 3 \\
\text { 2nd procedure: } 3 \rightarrow 1\end{array}$ & $\begin{array}{l}\text { unsatisfied } \\
\text { (persistent prolapse) }\end{array}$ & satisfied \\
\hline $\mathrm{F}$ & 41 & $\begin{array}{l}\text { 1st procedure: } 3 \rightarrow 3 \\
\text { 2nd procedure: } 3 \rightarrow 2\end{array}$ & $\begin{array}{l}\text { unsatisfied } \\
\text { (persistent prolapse) }\end{array}$ & unsatisfied \\
(persistent prolapse)
\end{tabular}


fied ( 3 because of prolapse and 1 because of bleeding). Eight of the 9 patients who underwent a second procedure for persistent prolapse were grade 3 patients (table 2). No significant correlation was found between the posttreatment result and the number of ligations placed, nor was a significant correlation found with the surgeon who performed the procedure or with operating time.

All patients were treated in daycare; none of them needed to stay overnight. Seven patients complained of pain that prolonged longer than 2 days; no one had pain longer than 7 days. The pain was treated with ibuprofen (400 mg NSAID b.i.d.). Mortality was $0 \%$ and morbidity $3 \%(1 \times$ urinary retention, $1 \times$ anal fissure, $1 \times$ bleeding in a patient with inadequate dosage of anticoagulant therapy (INR $>9)$ ).

\section{Discussion}

In a meta-analysis of 18 prospective randomized trials, rubber banding was found to be the most effective of the in-office procedures. It is associated with a lower recurrence rate, but more overall pain than sclerotherapy or infrared coagulation. In the studies described, an average of $13 \%$ of patients complained of postprocedural pain after rubber banding (range 0-60\%) [7]. The re-treatment rate for rubber banding varies widely. A systematic review revealed an overall $40 \%$ re-treatment rate for rubber banding (range 17-86\%) [2, 15].

The surgical procedures for the treatment of hemorrhoids seem to be more effective, with reported re-treatment rates of $0-20 \%[2,7]$. Unfortunately, the postprocedural pain for surgical hemorrhoidectomy is a major disadvantage. Patients report significantly more pain after surgical hemorrhoidectomy compared to rubber banding [7].

DG-HAL is a relatively new treatment modality. Although the procedure has been performed under local anesthesia using xylocaine gel, we opted for spinal anes- thesia [13]. This allows plenty of time to carefully detect and ligate all arterial signals without any patient discomfort. The procedure itself is easy to learn and takes only 15 min to perform. In our study, $88 \%$ of the patients had an improvement in hemorrhoidal gradation and $85 \%$ were satisfied with the result of the treatment. Although the follow-up period was relatively short, these results confirm those of other studies. Scheyer et al. [14] reported that $80 \%$ of their patients were free from pain and bleeding after a median 18 months of follow-up. However, about $40 \%$ were reported to have recurrent hemorrhoidal piles. Greenberg et al. [16] report $89 \%$ asymptomatic patients and an $11 \%$ re-treatment rate after 1 year follow-up. A randomized trial comparing hemorrhoidectomy and DG-HAL found no difference between recurrence rates in preoperative symptoms at 1 year follow-up [17].

The standard treatment for grade 2 and 3 hemorrhoids at our institution used to be rubber banding. In our experience, more than three rubber bands placed in one session gives discomfort to the patient. The relation between discomfort and number of bands placed has been both confirmed and denied in previous studies $[18,19]$. In our study, only $6 \%$ of the patients complain of pain after the procedure.

In our study, $88 \%$ of patients had posttreatment improvement and patient satisfaction was $85 \%$. Furthermore, there were no complications or side effects due to the spinal anesthesia reported. The re-treatment rate was $9 \%$, and a scant $6 \%$ of patients reported posttreatment pain. These results made us decide to use DG-HAL as the treatment of choice for symptomatic grade 2 and 3 hemorrhoids. In 2006 we began a randomized clinical trial to compare DG-HAL with rubber banding. Unfortunately, due to positive media coverage of DG-HAL, we were not able to obtain any informed consent for rubber banding. The trial has now stopped. We continue to follow our patient cohort and hope to report about the long-term follow-up in the future.
References
1 Janssen LWM: Consensus hemorroïden [in Dutch]. Ned Tijdschr Geneeskd 1994;138: 2106-2109.

-2 Shanmugam V, Thaha MA, Rabindranath KS, Campbell KL, Steele RJC, Loudon MA: Systematic review of randomized trials comparing rubber band ligation with excisional haemorrhoidectomy. Br J Surg 2005;92: 1481-1487.
3 Goligher J, Duthie H, Nixon H: Hemorrhoids or Piles. Surgery of the Anus, Rectum and Colon, ed 5. London, Bailliere Tindall, 1992, pp 144-145.

-4 Senapati A, Nicholls RJ: A randomised trial to compare the results of injection sclerotherapy with a bulk laxative alone in the treatment of bleeding haemorrhoids. Int J Colorectal Dis 1988;3:124-126. 
5 Porrett TR, Lunniss PJ: A prospective randomised controlled trial of consultant-led sclerotherapy compared with nurse practitioner-led non-invasive interventions in the treatment of patients with first and seconddegree haemorrhoids. Colorectal Dis 2001;3: 227-231.

6 Walker AJ, Leicester RJ, Nicholls RJ, Mann $\mathrm{CV}$ : A prospective study of infrared coagulation, injection and rubber band ligation in the treatment of haemorrhoids. Int J Colorectal Dis 1990;5:113-116.

$\checkmark 7$ MacRae HM, McLeod RS: Comparison of hemorrhoidal treatment modalities: a metaanalysis. Dis Colon Rectum 1995;38:687694.

-8 Johanson JF, Rimm A: Optimal non-surgical treatment of hemorrhoids: a comparative analysis of infrared coagulation, rubber band ligation, and injection sclerotherapy. Am J Gastroenterol 1992;87:1600-1606.

$\checkmark 9$ Hardy A, Chan CLH, Cohen CRG: The surgical management of haemorrhoids - a review. Dig Surg 2005;22:26-33.
10 Jayne DG, Botterill I, Ambrose NS, Brennan TG, Guillou PJ, O’Riordain DS: Randomized clinical trial of Ligasure versus conventional diathermy for day-case haemorrhoidectomy. Br J Surg 2002;89:428-432.

11 Peng BC, Jayne DG, Ho YH: Randomized trial of rubber band ligation vs. stapled hemorrhoidectomy for prolapsed piles. Dis Colon Rectum 2003;46:291-297.

12 Aigner F, Bodner G, Conrad F, Mbaka G, Kreczy A, Fritsch H: The superior rectal artery and it's branching pattern with regard to its clinical influence on ligation techniques for internal hemorrhoids. Am J Surg 2004; 187:102-108.

13 Morinaga K, Hasuda K, Ikeda T: A novel therapy for internal hemorrhoids: ligation of the hemorrhoidal artery with a newly devised instrument (Moricorn) in conjunction with a Doppler flowmeter. Am J Gastroenterol 1995;90:610-613.

14 Scheyer M, Antonietti E, Rollinger G, Mall H, Arnold S: Doppler-guided hemorrhoidal artery ligation. Am J Surg 2006;191:89-93.
15 Murie JA, Mackenzie I, Sim AJ: Comparison of rubber band ligation and haemorrhoidectomy for second- and third-degree haemorrhoids: a prospective clinical trial. Br J Surg 1980;67:768-768.

16 Greenberg R, Karin E, Avital S, Skornick Y, Werbin N: First 100 cases with Dopplerguided hemorrhoidal artery ligation. Dis Colon Rectum 2006;49:485-489.

17 Bursics A, Morvay K, Kupcsulik P, Flautner L: Comparison of early and one-year followup results of conventional hemorrhoidectomy and hemorrhoid artery ligation: a randomized study. Int J Colorectal Dis 2004;19: 176-180.

18 Lee HH, Spencer RJ, Beart RW: Multiple hemorrhoidal banding in a single session. Dis Colon Rectum 1994;37:37-41.

19 Chaleoykitti B: Comparative study between multiple and single rubber band ligation in one session for bleeding internal hemorrhoids: a prospective study. J Med Assoc Thai 2002;85:345-350. 